\title{
Potential cardioprotective peptides generated in Spanish dry-cured ham
}

\author{
Marta Gallego, Leticia Mora and Fidel Toldrá*
}

Instituto de Agroquímica y Tecnología de Alimentos (CSIC), Avenue Agustín Escardino 7, 46980, Paterna (Valencia), Spain

*Corresponding author: Fidel Toldrá, Instituto de Agroquímica y Tecnología de Alimentos (CSIC), Avenue Agustín Escardino 7, 46980, Paterna (Valencia), Spain. Tel: +34963900022 ext.2112; Fax: +34963636301; E-mail: ftoldra@iata.csic.es

DOI: $10.31665 / J F B .2019 .6188$

Received: April 05, 2019; Revised received \& accepted: June 29, 2019

Citation: Gallego, M., Mora, L., and Toldrá, F. (2019). Potential cardioprotective peptides generated in Spanish dry-cured ham. J. Food Bioact. 6: 110-117.

\begin{abstract}
Food-derived bioactive peptides are promising compounds for the prevention and treatment of cardiovascular diseases, the main cause of mortality in developed countries. The aim of this work was to determine the in vitro anti-inflammatory, antioxidant, and angiotensin I-converting enzyme (ACE-I) inhibitory activities of twenty-four peptides that were identified in Spanish dry-cured hams. For the first time, some peptides such as PSNPP, HCNKKYRSEM and FNMPLTIRITPGSKA showed anti-inflammatory activity expressed as platelet-activating factor-acetylhydrolase, autotaxin, and lipoxygenase inhibition. Peptides MDPKYR and TKYRVP were the strongest antioxidants, whereas GGVPGG, TKYRVP, and HCNKKYRSEM showed the highest ACE-I inhibitory activity. Additionally, several peptides such as KPVAAP, MDPKYR, TKYRVP, and HCNKKYRSEM exerted more than one of the assayed activities, increasing their health-enhancing potential. More studies are needed to evaluate the bioavailability of such peptides and their in vivo effect. This would contribute to consider dry-cured ham as a source of peptides beneficial for cardiovascular health.
\end{abstract}

Keywords: Bioactive peptides; Anti-inflammatory activity; Antioxidant activity; ACE-I inhibitory activity; Multifunctional peptides; Cardiovascular health.

\section{Introduction}

Cardiovascular diseases (CVD) are currently the main cause of mortality in developed countries, being hypertension, dyslipidaemia, and diabetes important risk factors associated with the development of heart diseases. Food-derived bioactive peptides constitute interesting compounds for the prevention and treatment of CVD as alternative to available pharmaceutical drugs that entail high costs and negative-side effects in the organism (Erdmann et al., 2008). Bioactive peptides are generally $2-20$ amino acids in length and are capable to exert positive health effects in the human body such as antihypertensive, antioxidant, anti-inflammatory, and antidiabetic activities, among others. Bioactive peptides may be generated, or lose part of its bioactivity, by the action of proteolytic enzymes during food processing and gastrointestinal digestion
(GI). Then, peptides must reach their target sites in an active form and significant quantity to exert their beneficial effects (Udenigwe and Aluko, 2012).

Many bioactive peptides have been reported to be naturally generated during the processing of Spanish dry-cured ham through the action of endogenous muscle enzymes along processing. Among them, angiotensin I-converting enzyme (ACE-I) inhibitory peptides are outstanding (Escudero et al., 2013a, 2014). Such ACE-I inhibitors prevent the formation of the vasoconstrictor angiotensin-II and the release of aldosterone in the Renin-Angiotensin-Aldosterone System (RAAS). Additionally, blood pressure regulation can be performed though the endothelin and nitric oxide (NO) systems, as well as other less studied mechanisms related to oxidative stress, vascular inflammation, and sympathetic nervous system (Majumder and Jianping, 2015).

Antioxidant peptides (Escudero et al., 2013b; Mora et al., 
2014), and dipeptidyl peptidase-IV (DPP-IV) inhibitory peptides with potential antidiabetic activity (Gallego et al., 2014a) have been also identified in Spanish dry-cured hams. These bioactive peptides might participate in the regulation of vascular functions, blood pressure, and inflammatory responses due to the link between metabolic pathways. In fact, oxidative stress is often associated with inflammatory processes, but exist other complex mechanisms of action for anti-inflammatory peptides related to RAAS, pro-inflammatory cytokines, pro-inflammatory signalling kinases, and integrin-dependent signalling (Chakrabarti et al., 2014; Schulz et al., 2011).

Although there is an absence of reports on the anti-inflammatory activity of peptides isolated from dry-cured ham, two recent studies in humans have suggested that the regular intake of drycured hams could contribute to cardiovascular health related to glucose and lipid metabolism, hypertension, and inflammatory processes (Martínez-Sánchez et al., 2017; Montoro-García et al,. 2017). Thus, the aim of this work was to determine the in vitro anti-inflammatory, antioxidant, and ACE-I inhibitory activities of twenty-four peptides isolated from dry-cured hams and identified in a previous study.

\section{Materials and methods}

\subsection{Chemicals and reagents}

Angiotensin I-converting enzyme from rabbit lung, captopril, fluorescein, 2,2'-azobis(2-methylpropionamidine) dihydrochloride (AAPH), 2,2'-azino-bis(3-ethylbenzothiazoline-6-sulfonic acid) diammonium salt (ABTS), and ( \pm )-6-hydroxy-2,5,7,8-tetramethylchromane-2-carboxylic acid (Trolox) were purchased from Sigma-Aldrich, Co. (St. Louis, MO, USA). $O$-aminobenzoylglycyl- $p$ nitro- $L$-phenylalanyl- $L$-proline (Abz-Gly- $p$-nitro-Phe-Pro-OH) trifluoroacetate salt was from Bachem AG. (Bubendorf, Switzerland) while potassium persulfate was from Panreac Química, SAU (Barcelona, Spain). PAF acetylhydrolase inhibitor screening assay kit (Item No. 10004380), autotaxin inhibitor screening assay kit (Item No. 700580), and lipoxygenase inhibitor screening assay kit (Item No. 760700) were supplied by Cayman Chemical Company (Ann Arbor, MI, USA). All chemicals and reagents were of analytical grade.

\subsection{Peptide synthesis}

Twenty-four peptides were selected, from a range of previously identified peptides in Spanish dry-cured hams, according to potential bioactivity based on the length, molecular weight, sequence, and composition in amino acids (Table 1). The selected peptides were synthesised (GenScript Corporation, Piscataway, NJ, USA) and the purity checked through liquid chromatography-mass spectrometry (LC-MS) analysis. Peptide solutions $(1 \mathrm{mM})$ were prepared for subsequent bioactivity assays.

\subsection{Anti-inflammatory activity}

\subsubsection{Platelet-activating factor-acetylhydrolase inhibition assay}

The platelet-activating factor-acetylhydrolase (PAF-AH) inhibitor kit was assayed in accordance with the manufacturers' instructions. The substrate 2-thio PAF is hydrolysed by the enzyme PAF-
$\mathrm{AH}$, generating free thiols that are colorimetrically detected using 5,5'-dithio-bis-(2-nitrobenzoic acid) (DNTB). Samples were assayed in triplicate and results expressed as percentage of PAF-AH inhibition.

\subsubsection{Autotaxin inhibition assay}

The autotaxin (ATX) inhibitor kit was assayed as described by the manufacturer. ATX cleaves bis-( $p$-nitrophenyl) phosphate, releasing the yellow product $p$-nitrophenol that is spectrophotometrically measured. Samples were assayed in triplicate and results expressed as percentage of ATX inhibition.

\subsubsection{Lipoxygenase inhibition assay}

Lipoxygenase (LOX) inhibitor kit was assyed as described by the manufacturer. In this assay, the hydroperoxides produced in the lipoxygenation reaction using 15-lipoxygenase are detected and measured. Samples were assayed in triplicate and results expressed as percentage of LOX inhibition.

\subsection{Antioxidant activity}

\subsubsection{Oxygen radical absorbance capacity (ORAC)}

Different concentrations of the peptides $(5-500 \mu \mathrm{M})$ were assayed in triplicate. For that, $140 \mu \mathrm{L}$ of sample in $75 \mathrm{mM}$ phosphate buffer (pH 7.4) was added $70 \mu \mathrm{L}$ of $200 \mathrm{nM}$ fluorescein and kept $15 \mathrm{~min}$ at $37^{\circ} \mathrm{C}$. After adding $70 \mu \mathrm{L}$ of $80 \mathrm{mM} \mathrm{AAPH}$, fluorescence was read every minute for $100 \mathrm{~min}$. The excitation and emission wavelengths were 485 and $538 \mathrm{~nm}$, respectively. Trolox $(2-16 \mu \mathrm{M})$ was used as standard and tryptophan as positive control. The ORAC values were determined by integrating the relative fluorescence curve and plotted against trolox concentration in order to obtain a standard curve. Results were expressed as nanomoles of trolox equivalents (TE) per mg of sample.

\subsubsection{ABTS radical scavenging capacity}

In order to perform the ABTS assay, $7 \mathrm{mM}$ of ABTS was dissolved in $2.45 \mathrm{mM}$ potassium persulfate, keeping it in the dark for $12-16$ $\mathrm{h}$ at room temperature to produce the radical cation $\mathrm{ABTS}^{\circ+}$. The $\mathrm{ABTS}^{\circ+}$ solution was diluted with $50 \mathrm{mM}$ phosphate buffer saline (PBS; pH 7.4) to obtain an absorbance of $0.70 \pm 0.02$ at $734 \mathrm{~nm}$. Different concentrations of the peptides $(0.1-2 \mathrm{mM})$ were assayed in triplicate. For that, $10 \mu \mathrm{L}$ of sample and $990 \mu \mathrm{L}$ of ABTS ${ }^{*+}$ solution was incubated $6 \mathrm{~min}$ and the absorbance measured at $734 \mathrm{~nm}$. The standard was trolox $(0.05-2 \mathrm{mM})$, ascorbic acid the positive control and PBS the negative control. The ABTS radical scavenging activity was determined and plotted against the trolox concentration. Results were expressed as nanomoles of TEAC (trolox equivalent antioxidant capacity) per mg of sample.

\subsection{ACE-I inhibitory activity}

The methodology developed by Sentandreu and Toldrá (2006) was followed. $50 \mu \mathrm{L}$ of sample was mixed with $50 \mu \mathrm{L}$ of ACE-I (3 $\mathrm{mU} / \mathrm{mL}$ in $150 \mathrm{mM}$ Tris buffer, $\mathrm{pH} \mathrm{8.3).} \mathrm{Then,} 200 \mu \mathrm{L}$ of substrate Abz-Gly- $p$-nitro-Phe-Pro-OH (0.45 mM in $150 \mathrm{mM}$ Tris buffer 
Table 1. Peptides previously identified in Spanish dry-cured ham and synthetised for testing their bioactivity

\begin{tabular}{|c|c|c|c|c|}
\hline Peptide & Protein of origin & Source* & $\begin{array}{l}\text { Previously as- } \\
\text { sayed bioactivity }\end{array}$ & References \\
\hline AAATP & Allantoicase & Spanish dry-cured ham (10m) & ACE inhibitor & Escudero et al. (2013a) \\
\hline AMNPP & Myosin-3 & Teruel dry-cured ham (14m), desalted & ACE inhibitor & Escudero et al. (2014) \\
\hline IAGRP & Titin & Teruel dry-cured ham $(14 \mathrm{~m})$, desalted & ACE inhibitor & Escudero et al. (2014) \\
\hline IKLPP & Myosin-IXb & Teruel dry-cured ham (14m), desalted & ACE inhibitor & Escudero et al. (2014) \\
\hline KPGRP & Titin & Teruel dry-cured ham (14m), desalted & ACE inhibitor & Escudero et al. (2014) \\
\hline KVLPG & Phosphoglycerate kinase 1 & Teruel dry-cured ham $(14 \mathrm{~m})$, desalted & ACE inhibitor & Escudero et al. (2014) \\
\hline PAPPK & Myosin light chain $1 / 3$ & Teruel dry-cured ham $(14 \mathrm{~m})$, desalted & ACE inhibitor & Escudero et al. (2014) \\
\hline PSNPP & Titin & Teruel dry-cured ham $(14 \mathrm{~m})$, desalted & ACE inhibitor & Escudero et al. (2014) \\
\hline TGLKP & Aspartate aminotransferase & Teruel dry-cured ham (14m), desalted & ACE inhibitor & Escudero et al. (2014) \\
\hline AAATPL & $\begin{array}{l}\text { Epithelial splicing } \\
\text { regulatory protein } 2\end{array}$ & Teruel dry-cured ham $(14 \mathrm{~m})$, desalted & ACE inhibitor & Escudero et al. (2014) \\
\hline AAPLAP & Myosin-XV & Teruel dry-cured ham $(14 \mathrm{~m})$, desalted & ACE inhibitor & Escudero et al. (2014) \\
\hline DVITGA & $\begin{array}{l}\text { Myosin light chain } \\
\text { phosphorylatable }\end{array}$ & Spanish dry-cured ham (10m) & ACE inhibitor & Escudero et al. (2013a) \\
\hline EEYPDL & Creatine kinase & Spanish dry-cured ham (10m) & - & $\begin{array}{l}\text { Escudero et al. (2013a), } \\
\text { Mora et al. (2014) }\end{array}$ \\
\hline GGVPGG & Elastin & Spanish dry-cured ham (10m) & Antioxidant & Mora et al. (2014) \\
\hline KAAAAP & Myosin light chain 3 & Teruel dry-cured ham $(14 \mathrm{~m})$, desalted & ACE inhibitor & Escudero et al. (2014) \\
\hline KPVAAP & Myosin-XV & Teruel dry-cured ham $(14 \mathrm{~m})$, desalted & ACE inhibitor & Escudero et al. (2014) \\
\hline MDPKYR & Titin & Spanish dry-cured ham (10m) & Antilisterial & Castellano et al. (2016) \\
\hline MPAWPI & $\begin{array}{l}\text { Aspartate b-hydroxylase } \\
\text { domain-containing prot } 1\end{array}$ & Spanish dry-cured ham (10m) & Antioxidant & Mora et al. (2014) \\
\hline TKYRVP & Titin & Spanish dry-cured ham (10m) & Antilisterial & Castellano et al. (2016) \\
\hline KAAAATP & $\begin{array}{l}\text { PR domain zinc } \\
\text { finger protein } 2\end{array}$ & Teruel dry-cured ham $(14 \mathrm{~m})$, desalted & ACE inhibitor & Escudero et al. (2014) \\
\hline AEEEYPDL & Creatine kinase & Spanish dry-cured ham (10m) & Antioxidant & $\begin{array}{l}\text { Mora et al. (2014), } \\
\text { Gallego et al. (2018) }\end{array}$ \\
\hline HCNKKYRSEM & Dynein heavy chain 3 & Spanish dry-cured ham (10m) & Antilisterial & Castellano et al. (2016) \\
\hline TSNRYHSYPWG & $\begin{array}{l}\text { Serine/threonine- } \\
\text { protein kinase }\end{array}$ & Spanish dry-cured ham (10m) & Antilisterial & Castellano et al. (2016) \\
\hline FNMPLTISRITPGSKA & $\begin{array}{l}\text { LIM domain-binding } \\
\text { protein } 3\end{array}$ & Spanish dry-cured ham (9m) & - & Gallego et al. (2014b) \\
\hline
\end{tabular}

*Type of dry-cured ham and curing time (in months) in which the peptide has been identified.

with $1.125 \mathrm{mM} \mathrm{NaCl}, \mathrm{pH} 8.3$ ) was added to start the reaction and the fluorescence measured after incubating $45 \mathrm{~min}$ at $37^{\circ} \mathrm{C}$. The excitation and emission wavelengths were 355 and $405 \mathrm{~nm}$, respectively. The assay was done in triplicate and captopril used as positive control. Results were expressed as percentage inhibition of ACE-I.

\subsection{Statistical analysis}

One-way analysis of variance (ANOVA) and Fisher's multiple range tests were performed using the software XLSTAT 2011 v5.01 (Addinsoft, Barcelona, Spain). Results were expressed as the mean of 3 replicates \pm standard deviations, and differences were considered significantly at $P<0.05$.

\section{Results and discussion}

\subsection{Anti-inflammatory activity of dry-cured ham peptides}

The anti-inflammatory activity of the peptides was evaluated by measuring inhibition percentages of PAF-AH, ATX, and LOX. Recently, a clinical study evaluated the cause-effect relationship between dry-cured ham consumption and cardiovascular effects, analysing the changes in monocytes and platelets as involved agents in inflammatory and thrombotic responses, which resulted affected 

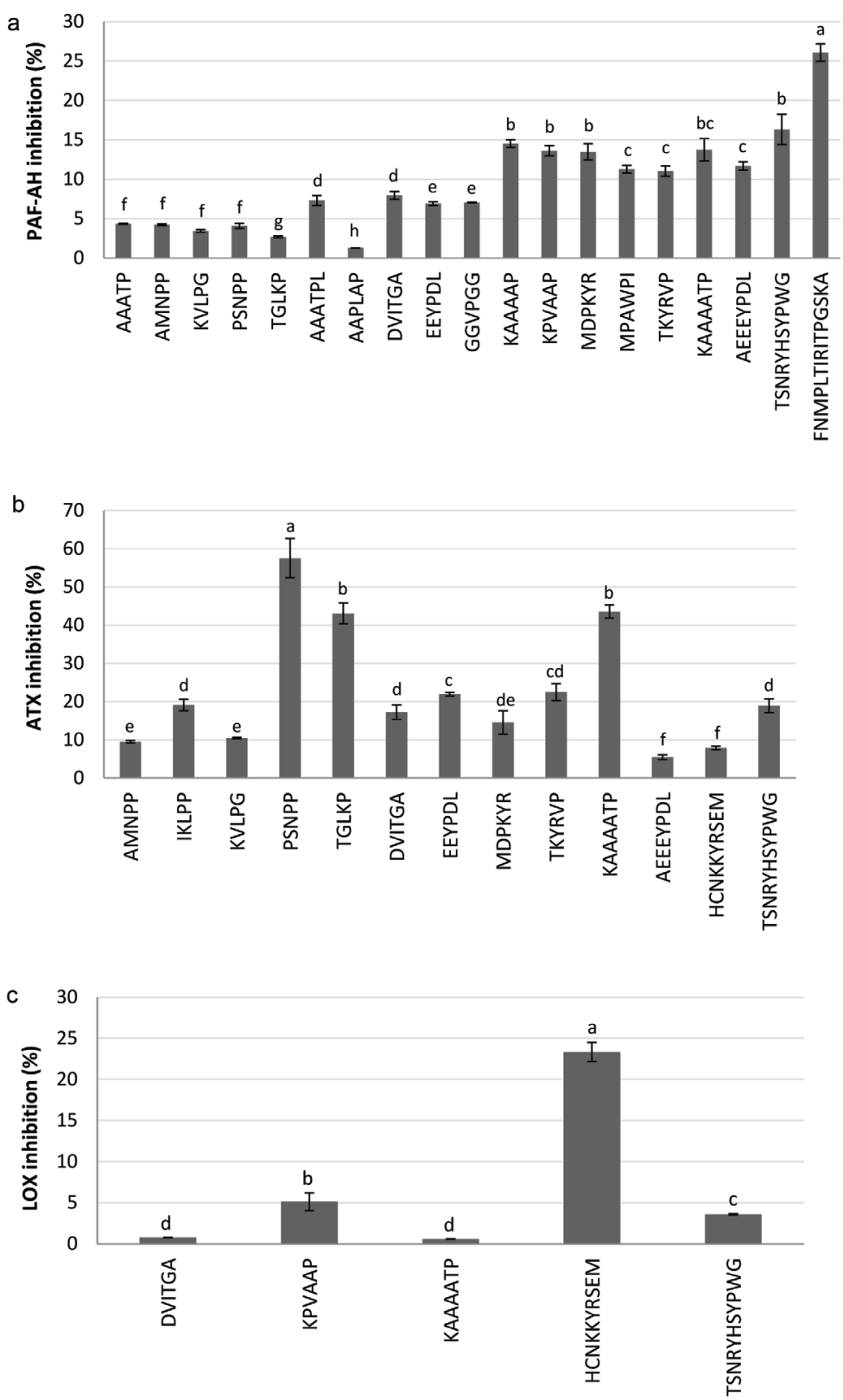

Figure 1. Anti-inflammatory activity of the dry-cured ham peptides expressed as a) platelet-activating factor-acetylhydrolase (PAF-AH) inhibitory activity, b) autotaxin (ATX) inhibitory activity, and c) lipoxygenase (LOX) inhibitory activity. Bar letters indicate significant differences among the values at $P<0.05$.

together with the levels of plasmatic P-selectin, monocyte chemoattractant protein-1 (MCP-1) and interleukin 6 in healthy subjects (Martínez-Sánchez et al., 2017).

Nineteen of the assayed peptides showed PAF-AH inhibitory activity, with values ranged from $1.28 \%$ to $26.06 \%$ (Figure 1a), and FNMPLTIRITPGSKA was the peptide showing the highest PAFAH inhibition. Recently, PAF-AH inhibitory peptides were found after the digestion of GI endogenous proteins such as lysozyme and trypsin (Dave et al., 2016), and after simulated GI digestion of dry-cured ham by-products (Gallego et al., 2019). Also a papain protein hydrolysate and seven identified peptides from the macroalga Palmaria palmata showed PAF-AH inhibitory activity, being NIGK the peptide with the highest inhibition, $50.74 \%$ at 1 $\mathrm{mg} / \mathrm{mL}$ (Fitzgerald et al., 2013). The PAF-AH enzyme plays a relevant role in vascular inflammation because it degrades oxidised phospholipids and generates the pro-inflammatory lysophosphatidylcholine and oxidised non-esterified fatty acids. So, this enzyme has been described to be a promising therapeutic target for the prevention of inflammation and atherosclerotic lesions (Wilensky et al., 2008).

The ATX enzyme is a lysophospholipase D that hydrolyses lysophosphatidylcholine to generate lysophosphatidic acid (LPA), which stimulates multiple cell signaling mechanisms. The ATX-LPA pathway is implicated in several pathologies including inflammation, tumor progression and nervous system diseases (Gierse et al., 2010). As can be seen in Figure 1b, thirteen peptides presented ATX 
inhibition, with values between $5.44 \%$ and $57.49 \%$. The peptide PSNPP was found as the strongest inhibitor, followed by TGLKP and KAAAATP.

When assaying LOX inhibition, only five of the assayed peptides showed inhibitory activity, with a maximum value of $23.33 \%$ for the peptide HCNKKYRSEM (see Figure 1c). The LOX enzyme plays a key role in unsaturated fatty acid metabolism, generating reactive hydroperoxides and lipid oxidative products. Besides, the LOX catalyses the formation of signal molecules such as leukotrienes and lipoxins, that when increased or after inappropriate production can promote the development of inflammation, atherosclerosis, and cancer (Schurink et al., 2006). Some peptides derived from $\beta$-casein (Schurink et al., 2006) and collagen proteins (Chen et al., 2018) as well as hydrolysates and peptide fractions obtained from edible insects (Zielińska et al., 2017) have been reported to exert in vitro anti-inflammatory potential expressed as LOX inhibition.

Despite the assayed dry-cured ham-derived peptides showed, in general, low in vitro anti-inflammatory activity, further studies could elucidate the sequences of other peptides contributing to the inhibitory activities as well as evaluate possible synergistic effects among peptides. Current challenges in the study of anti-inflammatory peptides are mainly due to the diversity and complexity of the inflammatory responses. In fact, each peptide could have a specific structure for their activity according to the followed molecular mechanism (Guha and Majumder, 2018). Up to date, several natural anti-inflammatory peptides derived from animal, plant, bacteria and marine organisms as well as synthetic peptides have been reported as potential candidates for reducing inflammation (Dadar et al., 2019). For example, the ACE-inhibitory tripeptide LSW from a soy protein hydrolysate has shown anti-inflammatory activity on vascular smooth muscle cells through its participation in several signaling pathways (Lin et al., 2017), whereas the casein-derived VPP modulated monocyte adhesion to vascular endothelium through its effect on a MAP kinase pathway (Aihara et al., 2009). The tripeptides IRW and IQW from egg ovotransferrin protein were able to limit the expression of pro-inflammatory cytokines and oxidative stress in endothelial cells (Liao et al., 2016; Majumder et al., 2013), and recently, longer egg-derived peptides such as DEDTQAMPFR and MLGATSL also showed anti-inflammatory effects on Caco-2 cells (Zhang et al., 2019). These studies suggest the importance of peptide structure in the regulatory pathway in which they participate to exert anti-inflammatory activity.

\subsection{Antioxidant activity of dry-cured ham peptides}

The antioxidant activity was measured by using ORAC and ABTS radical scavenging capacity assays because the lack of a single standard methodology for characterising the complete antioxidant activity of a sample (Huang et al., 2005)

The antioxidant results obtained using the ORAC assay are shown in Figure 2a, excluding peptides with values lower than $100 \mathrm{nmol} \mathrm{TE} / \mathrm{mg}$. Six peptides presented a significant antioxidant activity according to the ABTS assay (Figure 2b). Peptides MDPKYR and TKYRVP were the strongest antioxidants, showing ORAC values of $3,087.5$ and $2,886.8 \mathrm{nmol} \mathrm{TE} / \mathrm{mg}$, respectively, and ABTS values of 5,444.30 nmol TEAC/mg and 6,987.86 nmol TEAC/mg, respectively. The presence of tyrosine (Y) and the positive charged amino acids arginine $(\mathrm{R})$ and lysine $(\mathrm{K})$ in these peptide sequences could play an important role in this observed antioxidant activity, as well as could contribute to the antimicrobial activity of these peptides as previously reported by Castellano et al. (2016). Also other residues such as tryptophan (W), methionine $(\mathrm{M})$, cysteine $(\mathrm{C})$, histidine $(\mathrm{H})$ and phenylalanine $(\mathrm{F})$ contained in the sequence, as well as the structure and hydrophobicity of the peptides would determine their bioactivity and bioavailability (Liu et al., 2016).

The scavenging of reactive oxygen species (ROS) by antioxidant peptides prevents or retards protein and lipid oxidative processes in food, and can protect the body against oxidative stress and CVD. ROS may alter vascular function by oxidative modifications of nucleic acids and proteins, decrease NO bioavailability, and promote inflammation, apoptosis and other alterations. These processes can lead to functional and structural changes on the vascular system associated with hypertension and other CVD (Chakrabarti et al., 2014; Schulz et al., 2011).

\subsection{ACE-I inhibitory activity of dry-cured ham peptides}

The ACE-I inhibitory activity of the assayed peptides is shown in Figure 3. The highest activity (99.34\% inhibition) was observed for the peptide HCNKKYRSEM, whereas GGVPGG and TKYRVP presented inhibitory percentages over $80 \%$. Peptides TSNRYHSYPWG and FNMPLTIRITPGSKA also showed good ACE-I inhibition, with values around 70\%. Peptides HCNKKYRSEM and TKYRVP were previously assayed for antilisterial activity (Castellano et al., 2016) and GGVPGG for antioxidant activity measured by DPPH radical-scavenging and ferric-reducing power assays (Mora et al., 2014). Escudero et al. (2014) reported the ACE inhibitory activity of several peptides generated in Spanish dry-cured ham. Peptides IAGRP, AAPLAP, KAAAAP, and KPVAAP showed over $80 \%$ inhibition at a concentration of $1 \mathrm{mM}$, whereas peptides AAATP, IKLPP, KPGRP, TGLKP, and KAAAATP presented values ranged from $51 \%$ to $73 \%$ (data not shown in Figure 3 ). The stability of the peptide IAGRP against in vitro digestion and heat treatments was also described (Escudero et al., 2014). Additionally, a previous study using a Caco-2 cell monolayer evidenced the transepithelial transport of the intact peptide KPVAAP as well as the generation and absorption of fragments derived from the peptides AAPLAP and KPVAAP that maintained their ACE-I inhibitory activity (Gallego et al., 2016). The size of peptides as well as the composition and location of the amino acids contained in their sequences determine to a large extend their resistance to enzymatic hydrolysis and thus their bioactivity (Segura-Campos et al., 2011). The presence of amino acids such as proline $(\mathrm{P})$, alanine (A), and aromatic or aliphatic amino acids close to the $\mathrm{C}$-terminus as well as hydrophobic residues at the $\mathrm{N}$-terminus has been reported to promote its binding to ACE. In general, hydrophobic peptides display high affinity to the sub-sites located on the active site of ACE and inhibit the enzyme. Moreover, peptides containing proline and hydroxyproline have been reported to have high resistance to digestive enzymatic hydrolysis, improving their bioavailability (Segura-Campos et al., 2011).

The action of ACE-I inhibitory peptides in the RAAS by lowering blood pressure has been widely reported, although the activity observed in vitro does not always correlate with in vivo effects. The digestion by GI enzymes would determine the availability of peptides, since the effectiveness to inhibit ACE depends on the peptide structure and the absorption is greatly influenced by the peptide size. Furthermore, there are several pathways involved in regulating blood pressure, so peptides may also interact with enzymes other than ACE-I (Wu et al., 2017). Several studies have evidenced the antihypertensive action in spontaneously hypertensive rats (SHR) of dry-cured ham peptides (Escudero et al., 2013a; Mora et al., 2015) as well as of pork meat peptides generated by the action of digestive enzymes (Escudero et al., 2012). Moreover, a recent study with human volunteers suggested that the regular consumption of dry-cured ham would not modify arterial blood pressure and urine 

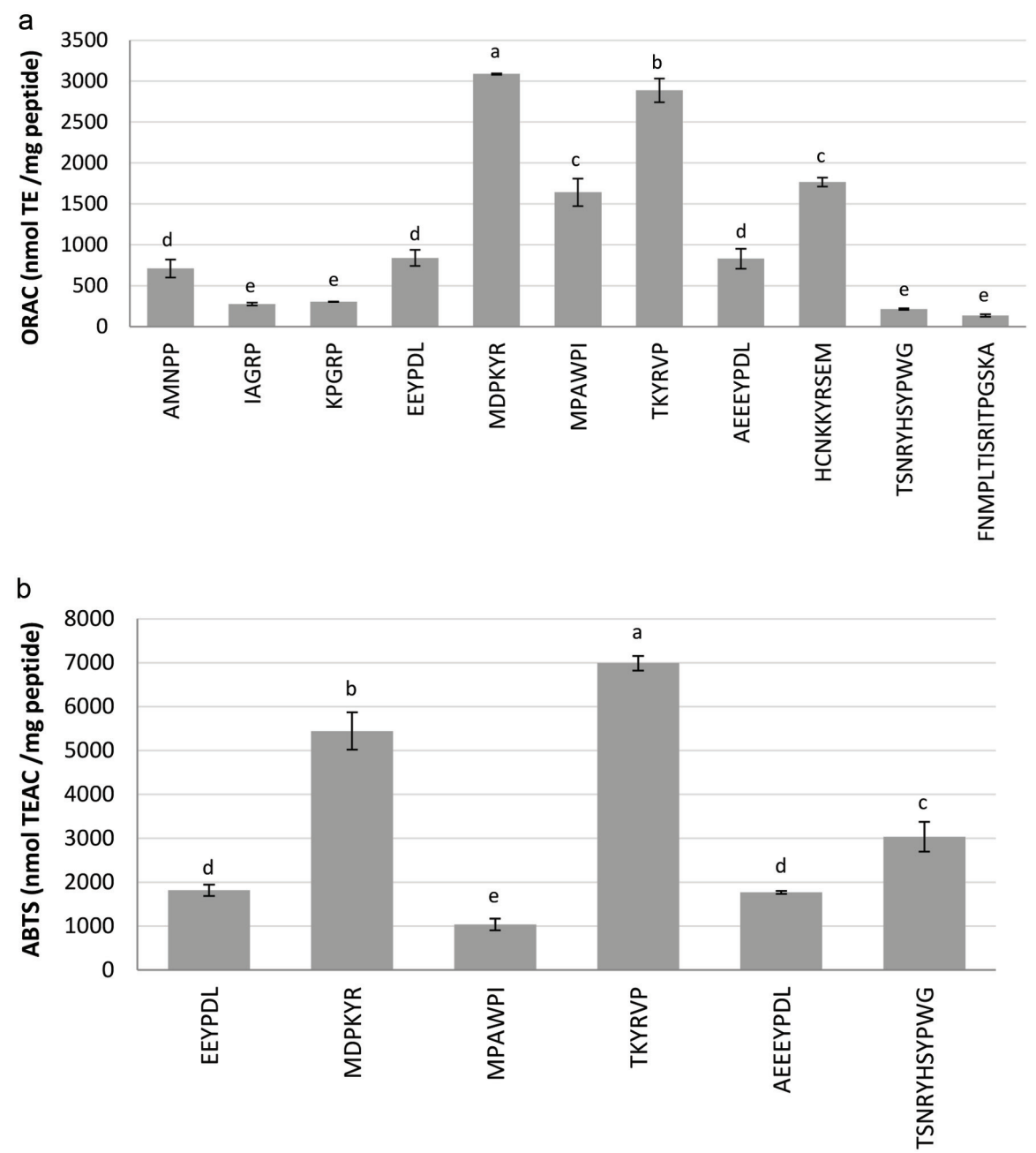

Figure 2. Antioxidant activity of the dry-cured ham peptides determined by a) oxygen radical absorbance capacity (ORAC) assay, and b) ABTS radical scavenging capacity. Bar letters indicate significant differences among the values at $P<0.05$.

sodium excretion despite increasing daily salt intake (MontoroGarcía et al., 2017), probably due to the participation of different antihypertensive mechanisms (Wu et al., 2017). ACE-I inhibitory peptides can prevent both the accumulation of the pro-inflammatory angiotensin II and the hydrolysis of bradykinin, leading to a reduction of free radical levels and an increase of $\mathrm{NO}$ release in the vascular system. Thus, these peptides might be used not only for the treatment of hypertension, but also to prevent oxidative stress and inflammation-associated CVD (Ferrario and Strawn, 2006).

\subsection{Multifunctional peptides}

Some food-derived bioactive peptides have been described to be multifunctional as they can exert two or more health-promoting activities that may or may not be related (Li and Aluko, 2010; Udenigwe and Aluko, 2012). So, proteins with high proportion of positively charged and hydrophobic residues would be a good source of multifunctional peptides (Rao et al., 2012). In our study, several peptides have displayed more than one bioactivity. The peptide KPVAAP exhibited high ACE-I inhibition, and certain anti-inflammatory activity expressed as PAF-AH and LOX inhibi- tion. As mentioned previously, this peptide could be transported intact through the intestinal epithelium (Gallego et al. 2016), suggesting its potential to exert several bioactive actions in the organism. Also peptides MDPKYR, TKYRVP, HCNKKYRSEM, and TSNRYHSYPWG, which were previously described as antibacterial peptides by Castellano et al. (2016), have displayed several in vitro bioactivities. So, MDPKYR and TKYRVP showed ACE-I inhibitory, antioxidant capacity in ORAC and ABTS assays, PAFAH inhibitory and ATX inhibitory activities. The peptide HCNKKYRSEM presented ORAC antioxidant activity and ACE-I, ATX and LOX inhibition, whereas TSNRYHSYPWG inhibited ACEI, PAF-AH, ATX, and LOX and displayed certain antioxidant activity in both ORAC and ABTS assays. Additionally, peptides TGLKP and KAAAATP have shown to be good ACE-I inhibitors and presented PAF-AH and ATX inhibitory activities. These results suggests the potential of some peptides generated in drycured ham as suitable candidates for further research on natural and multifunctional food ingredients to control and prevent CVD. Multifunctional peptides can act on two or more different receptors with complementary mechanism of action to gain additive or synergistic effect compared to single-activity peptides. Statistical modelling is a useful tool to study structure-activity relationships 


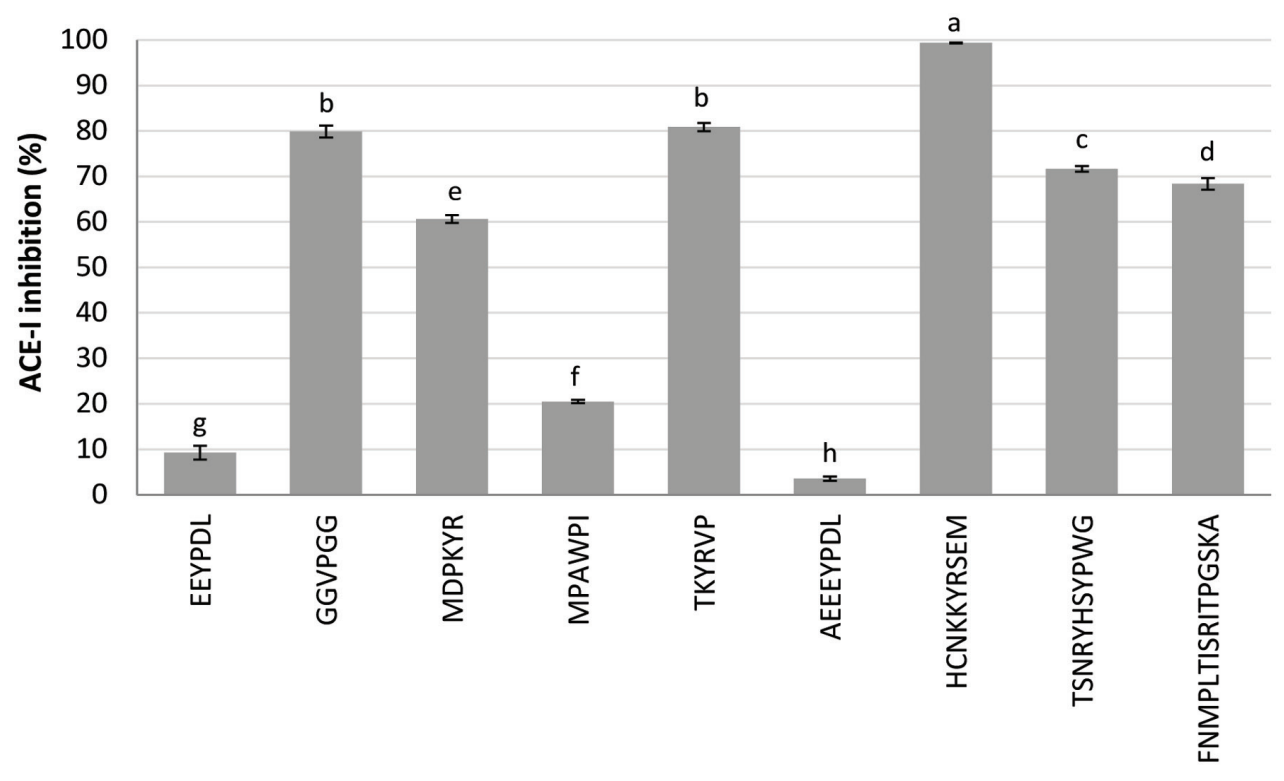

Figure 3. Angiotensin I-converting enzyme (ACE-I) inhibitory activity of the dry-cured ham peptides. Bar letters indicate significant differences among the values at $P<0.05$.

since the size and structural characteristics of the peptides are the key factors determining their molecular mechanisms and functions (Agyei et al., 2015). Bioavailability studies are also required to confirm potential health benefits of such peptides using animal models or clinical trials.

\section{Conclusions}

Different peptides from Spanish dry-cured hams have shown for the first time in vitro anti-inflammatory activity determined as PAF-AH, ATX, and LOX inhibition as well as confirmed ACE-I inhibition, and antioxidant activity. These results would support the beneficial effects on cardiovascular health previously observed in clinical trials in relation to hypertension and inflammatory processes. Additionally, this study has revealed that some of the assayed peptides such as KPVAAP, MDPKYR, TKYRVP, and HCNKKYRSEM can exert more than one bioactivity, increasing their health-enhancing potential. Additional studies are needed to evaluate the bioavailability and in vivo efficiency of these peptides.

\section{Acknowledgments}

Grants AGL2014-57367-R and AGL2017-89831-R and FEDER funds from the Spanish Ministry of Economy, Industry and Competitiveness and Intramural 201870E006 grant from CSIC are acknowledged. Ramón y Cajal postdoctoral contract to LM is also acknowledged.

\section{References}

Agyei, D., Potumarthi, R., and Danquath, M.K. (2015). Food-derived multifunctional bioactive proteins and peptides: Sources and production. Biotechnology of bioactive compounds. Sources and applications. In: Gupta, V.K., and Tuohy, M.G. (Ed.). Wiley Blackwell, Oxford, UK, pp.
483-506.

Aihara, K., Ishii, H., and Yoshida, M. (2009). Casein-derived tripeptide, ValPro-Pro (VPP), modulates monocyte adhesion to vascular endothelium. J. Atheroscler. Thromb. 16(5): 594-603.

Castellano, P., Mora, L., Escudero, E., Vignolo, G., Aznar, R., and Toldrá, F. (2016). Antilisterial peptides from Spanish dry-cured hams: Purification and identification. Food Microbiol. 59: 133-141.

Chakrabarti, S., Jahandideh, F., and Wu, J. (2014). Food-derived bioactive peptides on inflammation and oxidative stress. BioMed Res. Int. 2014: 608979.

Chen, Y.P., Liang, C.H., Wu, H.T., Pang, H.Y., Chen, C., Wang, G.H., and Chan, L.P. (2018). Antioxidant and anti-inflammatory capacities of collagen peptides from milkfish (Chanos chanos) scales. J. Food Sci. Technol. 55(6): 2310-2317.

Dadar, M., Shahali, Y., Chakraborty, S., Prasad, M., Tahoori, F., Tiwari, R., and Dhama, K. (2019). Antiinflammatory peptides: current knowledge and promising prospects. Inflamm. Res. 68: 125-145.

Dave, L.A., Hayes, M., Mora, L., Montoya, C.A., Moughan, P.J., and Rutherfurd, S.M. (2016). Gastrointestinal endogenous protein-derived bioactive peptides: an in vitro study of their gut modulatory potential. Int. J. Mol. Sci. 17(4): 482.

Erdmann, K., Cheung, B.W., and Schröder, H. (2008). The possible roles of food-derived bioactive peptides in reducing the risk of cardiovascular disease. J. Nutr. Biochem. 19(10): 643-654.

Escudero, E., Toldrá, F., Sentandreu, M.A., Hitoshi, N., and Arihara, K. (2012). Antihypertensive activity of peptides identified in the in vitro gastrointestinal digest of pork meat. Meat Sci. 91: 382-384.

Escudero, E., Mora, L., Fraser, P.D., Aristoy, M.C., Arihara, K., and Toldrá, F. (2013a). Purification and identification of antihypertensive peptides in Spanish dry-cured ham. J. Proteomics 78: 499-507.

Escudero, E., Mora, L., Fraser, P.D., Aristoy, M.C., and Toldrá, F. (2013b). Identification of novel antioxidant peptides generated in Spanish drycured ham. Food Chem. 138(2-3): 1282-1288.

Escudero, E., Mora, L., and Toldrá, F. (2014). Stability of ACE inhibitory ham peptides against heat treatment and in vitro digestion. Food Chem. 161: 305-311.

Ferrario, C.M., and Strawn, W.B. (2006). Role of the renin-angiotensin-aldosterone system and proinflammatory mediators in cardiovascular disease. Am. J. Cardiol. 98(1): 121-128.

Fitzgerald, C., Gallagher, E., O'Connor, P., Prieto, J., Mora-Soler, L., Grealy, M., and Hayes, M. (2013). Development of a seaweed derived platelet activating factor acetylhydrolase (PAF-AH) inhibitory hydrolysate, 
synthesis of inhibitory peptides and assessment of their toxicity using the Zebrafish larvae assay. Peptides 50: 119-124.

Gallego, M., Aristoy, M.C., and Toldrá, F. (2014a). Dipeptidyl peptidase IV inhibitory peptides generated in Spanish dry-cured ham. Meat Sci. 96(2): 757-761.

Gallego, M., Mora, L., Fraser, P.D., Aristoy, M.C., and Toldrá, F. (2014b). Degradation of LIM domain-binding protein three during processing of Spanish dry-cured ham. Food Chem. 149: 121-128.

Gallego, M., Grootaert, C., Mora, L., Aristoy, M.C., Van Camp, J., and Toldrá, F. (2016). Transepithelial transport of dry-cured ham peptides with ACE inhibitory activity through a Caco-2 cell monolayer. J. Funct. Foods 21: 388-395.

Gallego, M., Mora, L., and Toldrá, F. (2018). Characterisation of the antioxidant peptide AEEEYPDL and its quantification in Spanish dry-cured ham. Food Chem. 258: 8-15.

Gallego, M., Mora, L., Hayes, M., Reig, M., and Toldrá, F. (2019). Peptides with potential cardioprotective effects derived from dry-cured ham byproducts. J. Agric. Food Chem. 67(4): 1115-1126.

Gierse, J., Thorarensen, A., Beltey, K., Bradshaw-Pierce, E., Cortes-Burgos, L., Hall, T., Johnston, A., Murphy, M., Nemirovskiy, O., Ogawa, S., Pegg, L., Pelc, M., Prinsen, M., Schnute, M., Wendling, J., Wene, S., Weinberg, R., Wittwer, A., Zweifel, B., and Masferrer, J. (2010). A novel autotaxin inhibitor reduces lysophosphatidic acid levels in plasma and the site of inflammation. J. Pharmacol. Exp. Ther. 334(1): 310-317.

Guha, S., and Majumder, K. (2018). Structural-features of food-derived bioactive peptides with anti-inflammatory activity: A brief review. J. Food Biochem. 41(1): e12531.

Huang, D., Ou, B., and Prior, R.L. (2005). The chemistry behind antioxidant capacity assays. J. Agric. Food Chem. 53(6): 1841-1856.

Li, H., and Aluko, R.E. (2010). Identification and inhibitory properties of multifunctional peptides from pea protein hydrolysate. J. Agric. Food Chem. 58(21): 11471-11476.

Liao, W., Chakrabarti, S., Davidge, S.T., and Wu, J. (2016). Modulatory effects of egg white ovotransferrin-derived tripeptide IRW (Ile-Arg-Trp) on vascular smooth muscle cells against angiotensin II stimulation. J. Agric. Food Chem. 64(39): 7342-7347.

Lin, Q., Liao, W., Bai, J., Wu, W., and Wu, J. (2017). Soy protein-derived ACE-inhibitory peptide LSW (Leu-Ser-Trp) shows anti-inflammatory activity on vascular smooth muscle cells. J. Funct. Foods 34: 248-253.

Liu, R., Xing, L., Fu, Q., Zhou, G.H., and Zhang, W.G. (2016). A review of antioxidant peptides derived from meat muscle and by-products. Antioxidants 5(3): 32

Majumder, K., Chakrabarti, S., Davidge, S.T., and Wu, J. (2013). Structure and activity study of egg protein ovotransferrin derived peptides (IRW and IQW) on endothelial inflammatory response and oxidative stress. J. Agric. Food Chem. 61(9): 2120-2129.

Majumder, K., and Jianping, W. (2015). Molecular targets of antihypertensive peptides: understanding the mechanisms of action based on the pathophysiology of hypertension. Int. J. Mol. Sci. 16(1): 256-283.

Martínez-Sánchez, S.M., Minguela, A., Prieto-Merino, D., Zafrilla-Rentero,
M.P., Abellán-Alemán, J., and Montoro-García, S. (2017). The effect of regular intake of dry-cured ham rich in bioactive peptides on inflammation, platelet and monocyte activation markers in humans. Nutrients 9: 321.

Montoro-García, S., Zafrilla-Rentero, M.P., Celdrán-de Haro, F.M., Piñerode Armas, J.J., Toldrá, F., Tejada-Portero, L., and Abellán-Alemán, J. (2017). Effects of dry-cured ham rich in bioactive peptides on cardiovascular health: A randomized controlled trial. J. Funct. Foods 38: 160-167.

Mora, L., Escudero, E., Fraser, P.D., Aristoy, M.C., and Toldrá, F. (2014). Proteomic identification of antioxidant peptides from 400 to 2500 Da generated in Spanish dry-cured ham contained in a size-exclusion chromatography fraction. Food Res. Int. 56: 68-76.

Mora, L., Escudero, E., Arihara, K., and Toldrá, F. (2015). Antihypertensive effect of peptides naturally generated during Iberian dry-cured ham processing. Food Res. Int. 78: 71-78.

Rao, S., Sun, J., Liu, Y., Zeng, H., Su, Y., and Yang, Y. (2012). ACE-inhibitory peptides and antioxidant peptides derived from in vitro digestion hydrolysate of hen egg white lysozyme. Food Chem. 135: 1245-1252.

Schulz, E., Gori, T., and Münzel, T. (2011). Oxidative stress and endothelial dysfunction in hypertension. Hypertens. Res. 34(6): 665.

Schurink, M., Van Berkel, W.J., Wichers, H.J., and Boeriu, C.G. (2006). Identification of lipoxygenase inhibitory peptides from $\beta$-casein by using SPOT synthesis. ChemBioChem. 7(5): 743-747.

Segura-Campos, M., Chel-Guerrero, L., Betancur-Ancona, D., and Hernandez-Escalante, V.M. (2011). Bioavailability of bioactive peptides. Food Rev. Int. 27(3): 213-226.

Sentandreu, M.A., and Toldrá, F. (2006). A rapid, simple and sensitive fluorescence method for the assay of angiotensin-I converting enzyme. Food Chem. 97(3): 546-554.

Udenigwe, C.C., and Aluko, R.E. (2012). Food protein-derived bioactive peptides: production, processing, and potential health benefits. J. Food Sci. 77(1): R11-24.

Wilensky, R.L., Shi, Y., Mohler, E.R. 3rd, Hamamdzic, D., Burgert, M.E., Li, J., Postle, A., Fenning, R.S., Bollinger, J.G., Hoffman, B.E., Pelchovitz, D.J., Yang, J., Mirabile, R.C., Webb, C.L., Zhang, L., Zhang, P., Gelb, M.H., Walker, M.C., Zalewski, A., and Macphee, C.H. (2008). Inhibition of lipoprotein-associated phospholipase $\mathrm{A} 2$ reduces complex coronary atherosclerotic plaque development. Nat. Med. 14: 1059-1066.

Wu, J., Liao, W., and Udenigwe, C.C. (2017). Revisiting the mechanisms of ACE inhibitory peptides from food proteins. Trends Food Sci. Technol. 69: 214-219.

Zhang, M., Zhao, Y., Yao, Y., Xu, M., Du, H., Wu, N., and Tu, Y. (2019). Isolation and identification of peptides from simulated gastrointestinal digestion of preserved egg white and their anti-inflammatory activity in TNF- $\alpha$-induced Caco-2 cells. J. Nutr. Biochem. 63: 44-53.

Zielińska, E., Baraniak, B., and Karaś, M. (2017). Antioxidant and anti-inflammatory activities of hydrolysates and peptide fractions obtained by enzymatic hydrolysis of selected heat-treated edible insects. Nutrients 9(9): 970. 